\title{
LXXXVI. On the agency of electricity on animal secretions
}

\author{
Wm. H. Wollaston M.D. Sec. R.S.
}

To cite this article: Wm. H. Wollaston M.D. Sec. R.S. (1809) LXXXVI. On the agency of electricity on animal secretions, Philosophical Magazine Series 1, 33:134, 488-490, DOI: $10.1080 / 14786440908562909$

To link to this article: http://dx.doi.org/10.1080/14786440908562909

曲 Published online: 18 May 2009.

Submit your article to this journal $\lceil\pi$

LII Article views: 2

Q View related articles $₫$ 
without any vividness of effect, and the compounds are highly inflammable, and emit ammonia, and the one phosphuretted and the other sulphuretted hydrogen gas, by the action of water.

[T'a be continued.]

LXXXVI. On the Agency of Electricity on Animal Secretions. By WM. H. Wollaston, M.D., Sec. R.S.

A ${ }_{\mathrm{T}}$ the time when Mr. Davy first communicated to me bis important experiments on the separation and transfer of chemical agents by means of the Voltaic apparatus, which was in the autumn of 1806, I was forcibly struck with the probability that animal secretions were affected by the agency of a similar electric power; since the existence of this power in some animals was fully proved by the phænomena of the Torpedo, and of the Gymnotus Electricus; and since the universal prevalence of similar powers of lower intensity in other animals was rendered highly probable by the extreme suddenness with which the nervous influence is communicated from one part of the living system to another.

And though the separation of chemical agents, as well as their transfer to a distance, and their transition through solids, and through fluids which might be expected to oppose their progress, had not then been effected but by powerful batteries; yet it appeared highly probable that the weakest electric energies might be capable of producing the same effects, though more slowly in proportion to the weakness of the powers employed.

I accordingly at that time made an experiment for clucidating this hypothesis, and communicated it to $\mathrm{Mr}$. Davy and to others of my friends. But though it was conclusive with regard to the sufficiency of very feeble powers, it did not appear deserving of publication, until I could adduce some evidence of the actual employment of such means in the animal œconmy.

As I am not accustomed to making experiments on living animals, 
animals, I had deferred pursuing the application of my theory, until it was again brought back to my mind by finding that the same thought had occurred to Dr. Young. And as it has already been printed some months in the Syllabus of his Course of Medical Lectures, I had for the present relinquished all thoughts of recording conjectures, which, if not well founded, might retard the progress of science.

But since some experiments relating to the same inquiry are now about to be published by $\mathrm{Mr}$. Home, it may perhaps be of use to add my experiment to the general stock of information, although $I$ have not myself improved upon it by any further consideration, and am not yet enabled to confirm the hypothesis, which it appeared to support, by any new arguments.

The experiment was conducted as follows :

I took a piece of glass tube about three quarters of an inch in diameter and nearly two inches long, open at both ends, and covered one of them with a piece of clean bladder. Into this little vessel I poured some water in which I had dissolved $\frac{1}{240}$ of its weight of salt; and after placing it upon a shilling with the bladder slightly moistened externally, I bent a wire of zinc so, that while one extremity rested on the shilling the other might be immersed about an inch in the water. By successive examination of the external surface of the bladder, I found that even this feeble power occasioned sorla to be separated from the water, and to transude through the substance of the bladder. The presence of alkali was discernible by the application of reddened litmuspaper after two or three minutes, and was generally manifest even by the test of turmeric before five minutes had expired.

The efficacy of powers so feeble as are here called into action, tends to confirm the conjecture that similar agents may be instrumental in effecting the various animal secretions, which have not yet been otherwise explained. The qualities of each secreted fluid may hereafter instruct us as to the species of electricity that prevails in each organ of the body.

For instance, the general redundance of acid in urine, though 
though secreted from blood that is known to be alkaline, appears to indicate in the kidneys a state of positive electricity; and since the proportion of alkali in bile seems to be greater than is contained in the blood of the same animal, it is not improbable that the secreting vessels of the liver may be comparatively negative.

With such views of the vital functions it becomes an interesting subject of inquiry, what other organs may also be considered as permanently different in their state of electricity, and what others may possibly be subject to temporary states of opposite electric energies, and may, by means of such relation, produce the most powerful effects in the animal œconomy.

LXXXVII, Report of Surgical Cases in the City and Finsbury Dispensaries for Octoler, Novemler, and December, 1808. With the Dissection of a singular Fotus. By JoHn TAUNTON, Esq.

$I_{N}$ October, November, and December, there were admitted on the books of the City and Finsbury Dispensaries 738 surgical patients.

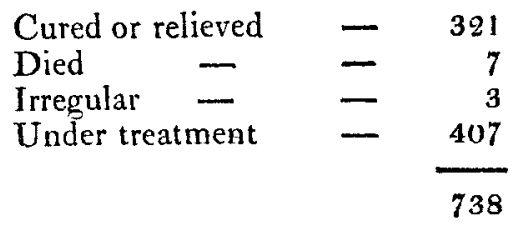

During the year 1808 , there have been admitted on the books of the City Dispensary 3105 patients.

Cured or relieved - 3069

Discharged for irregularity 5

Died - $\quad 31$

\section{5}

The expense of the City Dispensary for the year 1808, including every item of disbursement, amounts only to $575 l .9 s$. 1d.; a sum comparatively small to the benefits derived by the lower order of society, by persons incapable of providing

either 